\title{
E-DESAFIO - Uma proposta de capacitação de tutores para a gestão do conhecimento na Educação a Distância
}

\author{
Andréia F. Ramos* \\ Beatriz Regina Tavares Franciosi* \\ Flávia Aragones Almeida \\ Pricila Kohls dos Santos* \\ Leticia Lopes Leite
}

\begin{abstract}
Resumo
$O$ presente artigo tem como objetivo apresentar os primeiros passos da implantação do E-Desafio na PUCRS VIRTUAL (unidade de Educação a Distância da PUCRS). O E-Desafio é, um jogo interativo criado para a gestão de conhecimento na capacitação de tutores. Relatamos a experiência da formação de uma equipe multidisciplinar para a elaboração, o desenvolvimento e a implantação do jogo, bem como, dos aportes teóricos e metodológicos. É o resultado da iniciativa de unir a formação de pessoas com a tecnologia, inseridos na cultura da função do tutor em Educação a Distância.
\end{abstract}

Palavras- Chave: Educação a Distância; Educação Continuada; tutoria.

\begin{abstract}
This article aims to present the first step of the E-Chalenger implementation, at PUCRS Virtual/RS, Brazil (Distance Education Center - PUCRS Virtual). The E-Chalenger is an interactive game created for the e-moderating of knowledge in management qualification. We have reported the experience of forming a team comprised by professionals from various subjects for the elaboration, development and introduction of the game as well as' its theoretical and methodological bases. It is a result of an iniciative to unify the training of e-moderators and technology, all of them included in the $e$ moderator culture of Distance Education.
\end{abstract}

Keywords:; Distance Education; Continuous Education; Training

\footnotetext{
Mestranda em Educação pela Pontifícia Universidade Católica do Paraná (PUCPR) - Curitiba - PR — Brasil — deia2662@yahoo.com.br

" Coordenadora da PUCRS VIRTUAL - Pontifícia Universidade Católica do Rio Grande do Sul (PUCRS) Porto Alegre — RS — Brasil — bea@pucrs.br

".** Mestre em Psicologia Social e da Personalidade (PUCRS) Porto Alegre - RS - Brasil — almeida.fl@gmail.com Graduanda em Pedagogia Multimeios e Informática Educativa Pontifícia Universidade Católica do Rio Grande do Sul (PUCRS) _ pricilas.ead@pucrs.br

Mestre em Ciência da Computação - Universidade Federal do Rio Grande do Sul (UFRGS) — Ileite@inf.pucrs.br V.3 $\mathrm{N}^{\circ} 2$, Novembro, 2005
} 


\section{E-DESAFIO - Uma proposta de capacitação de tutores para a gestão do conhecimento na Educação a Distância}

\section{Introdução}

As considerações acerca da capacitação de tutores em Educação a Distância são constantes e de fundamental importância. Hoje, no contexto da tutoria, muitas são as experiências vivenciadas pelas diversas instituições de ensino no Brasil e no mundo. Após diversas oportunidades de capacitar pessoas para realizar o trabalho de mediação tecnológica e humana, surge a demanda de formar e desenvolver profissionais para a gestão do conhecimento em Educação a Distância.

A partir desta constatação, sentiu-se a necessidade de encontrar ferramentas que estivessem diretamente ligadas à cultura da tutoria da PUCRS VIRTUAL. Percebeu-se, inicialmente que os atuais modelos de formação não estavam atingindo, a contento, os objetivos da unidade. Desta forma, reuniu-se uma equipe multidisciplinar, que teve como desafio encontrar soluções para a capacitação de tutores em EAD. A partir de encontros semanais, de constantes brainstorms, de leituras e estudos, a idéia do EDESAFIO foi concebida. Psicólogos, Pedagogos da área de multimeios, profissionais da Computação debruçaram-se e estruturaram o E-DESAFIO, que se propõe a capacitar pessoas através da idéia de um jogo de negócios. Ele apresenta estudos de casos e desafios constantes, dentre outras atividades, sendo que as problemáticas propostas devem ser resolvidas por equipes formadas pelos alunos que participam do jogo.

$\mathrm{Na}$ implementação da proposta, optou-se por utilizar o Moodle, uma plataforma baseada em software livre, que entra em campo como ferramenta gerenciadora do ambiente de aprendizagem, oferecendo as ferramentas de comunicação e informação, para viabilização do jogo.

Desta forma, as equipes ao buscarem a solução dos casos propostos, vão encontrando diversas atividades e ferramentas dentro do ambientes. Cabe ressaltar que todos os casos propostos, os dilemas e as tarefas têm como pano de fundo situações-problema que estão diretamente relacionadas ao dia-a-dia de um tutor.

Usaremos o método do estudo de caso para contextualizar e situar a experiência da criação, e desenvolvimento do E-DESAFIO, pois a estratégia preferida quando se colocam questões do tipo "como" e "por que", quando o pesquisador tem pouco controle sobre os eventos e quando o foco se encontra em fenômenos contemporâneos inseridos em algum contexto da vida real. (YIN, 2001, p. 19).

Neste momento, o presente relato de experiência tem o cunho descritivo de trazer à luz das discussões teórico-práticas, a forma como se deu o processo do E-DESAFIO, quais são as suas potencialidades, as suas limitações e as sugestões para o futuro da capacitação de pessoas através das Tecnologias de Informação e Comunicação (TIC). (YIN, 2001)

\section{Aportes Teóricos}


Desde muito tempo, há uma grande preocupação social em desenvolver pessoas na sua potencialidade, seja para atingir fins mercadológicos e/ou sociais. Desta forma, entendemos que ao reunirmos em uma mesma discussão educação, tecnologias, capacitação e formação de pessoas voltadas para a Educação a Distância, estamos dizendo que a mera veiculação de recursos pela Internet não possibilita o deslocamento do foco do ensino para a aprendizagem.

Acreditamos que para que isto aconteça é necessário dispor de "novas" metodologias viabilizadas através de "novas" tecnologias, ou seja, integração entre conteúdos e estratégias de mediação da interação através das TIC. Esta nos mostra que hoje, há um campo de atuação amplo para o tutor, ou seja, existem funções de mediação tecnológica e humana dentro de instituições que promovem a Educação a Distância e a capacitação de pessoas pela rede mundial de computadores. Neste sentido, o tutor passa a ser um elo entre o virtual e o real, tornando-se assim um gestor do conhecimento, que tem por objetivo estimular e articular o conhecimento, visando atingir a excelência e proporcionar o compartilhamento das informações, envolvendo assim a promoção das relações humanas e do uso da tecnologia voltadas para a Educação.

Dando suporte a este contexto, utilizamos como recurso de integração um ambiente de aprendizagem que teve como função armazenar e garantir a segurança das informações trocadas e experienciadas ao longo do jogo. Dessa integração resultam os ambientes de aprendizagem cujo cenário é um espaço de informação (página de disciplina ${ }^{\mathrm{i}}$ ), disponibilizado pelo meio tecnológico através do qual é possível a interação e a mediação orientadas pelas dimensões da aprendizagem - interação, cooperação, cognição, metacognição e afeto (no sentido de sentir-se afetado) (MEDEIROS e FARIA, 2003). Nos espaços de comunicação produzidos nesses ambientes, as pessoas podem expandir continuamente sua capacidade de criar, de desenvolver novos padrões de raciocínio, de aprender continuamente através da ação em grupo e individual somando forças e conhecimento.

É importante aproveitar a potencialidade do meio digital para estabelecer conexões não seqüenciais entre as partes, ou seja, possibilitar a expansão da abrangência e profundidade de conteúdos/assuntos/temas. Há de se destacar que para construir estas conexões e interconexões sobre as fronteiras artificialmente criadas pela mente, o professor deve assumir o papel de agente pontifex ${ }^{i i}$, ou seja, o professor coloca-se como elo de ligação entre os alunos, entre o ambiente e no processo de aprendizagem e colaboração. Assumindo assim o papel de mediador onde deve estar disposto a ouvir, negociar, equilibrar, ajustar, enfim, mediar. Essa postura requer do professor presença mais constante e um envolvimento cada vez maior com o que os alunos estão aprendendo, pois será sua a tarefa de realinhar metas, auxiliar nas decisões, aproximar as pessoas para que a aprendizagem seja efetiva e significativa.

Todos aprendem, mas chega um momento em que a interação com outros sujeitos e a presença de novos estímulos são necessários para que o aprendiz supere momentos de dificuldades e avance para novas de aprendizagens. (VIGOTSKY, 1998).

Neste contexto, a figura do tutor é importante, pois ele estará atento às formas como se dá a constituição das relações humanas nos ambientes de aprendizagem, de forma a promover a motivação, a interação e a constituição do grupo.

Um outro pressuposto da equipe do E-DESAFIO é que tanto o tutor quanto o co-autoriii devem proporcionar o "conhecimento na ação, reflexão na ação e reflexão sobre a ação e sobre a reflexão na ação". (SCHÖN apud BEHRENS, 1996, p. 116). Assim o aluno, 
atuando como co-autor do processo de aprendizagem, também deve estar suscetível à interação para a construção comum do conhecimento visando diferentes saberes como resultado de novas formas de pensar e agir, onde cada um ocupa um espaço único, singular e em constante evolução.

A co-autoria possibilita a realização de atividades que, favorecem a autonomia, o senso de responsabilidade, uma vez que a qualidade dos resultados dependem do grupo. Esta responsabilidade trás consigo a noção do trabalho colaborativo e do aprender com o outro e com o grupo.

O delineamento da nova proposta de capacitação de tutores passa pela inclusão de objetos de aprendizagem $^{\text {iv }}$ visando o acoplamento estrutural da cognição vertical, multireferencial e multidimensional. Ou seja, estar imerso em ambientes cujos objetos são sempre inacabados uma vez que a conexão entre objetos de aprendizagem sempre pode ser alterada produzindo, dinamicamente, novos objetos.

A experiência do E-DESAFIO está sendo vivida, construída e implantada.

“(...) análise de ações pessoais dentro de contextos histórico-sociais mais amplos, pode contribuir para a superação de algumas perspectivas reducionistas (ainda comuns) da formação do professor virtual, tais como: (1) o simples treinamento do professor em aspectos tecnológicos (de software ou hardware) ou em técnicas de interação on-line (para uso de email, chats, listas de discussão etc.); (2) a ênfase na experimentação prática, em que se aprende simplesmente fazendo, sem um estudo mais aprofundado e sistemático sobre o assunto; (3) a ausência de uma preocupação com o contexto social, político e histórico em que vem se desenvolvendo a educação via redes de comunicação". (TAVARES, 2002).

O E-DESAFIO, mais a combinação de objetos de aprendizagem à luz da moldura teórico-prática, definida a partir das idéias de Vigotsky, 1984; Habermas, 1987; Deleuze-Guatarri, 1995; Morin, 1996 e Lévy, 1999, deve possibilitar a superação do desafio da produção de ambientes promotores da interação e da cooperação, dos processos cognitivos e metacognitivos, assim como do desenvolvimento da autonomia e de ações argumentativas.

\section{O Jogo}

O que é E-DESAFIO? É um jogo interativo, que tem como objetivo desenvolver competências humanas e tecnológicas, voltadas para a prática da tutoria em Educação a Distância. Através de cases práticos, desafios lançados no decorrer da semana, de encontros virtuais para feedback. Desta forma, as equipes trocam idéias e buscam soluções criativas para os problemas apresentados.

O E-DESAFIO tem como tema: "O papel do tutor na gestão do conhecimento na Educação a Distância”, sendo que ele se adapta às necessidades do mercado. É um jogo não linear. Desta forma, as equipes irão inscrever-se a qualquer tempo e hora.

Não há uma ordem para a escolha dos casos a serem solucionados. Pode-se utilizar qualquer tecnologia, bem como materiais externos e internos ao ambiente. Será utilizada a plataforma de e-learning Moodle sobre a qual o jogo será implementado e as equipes terão um espaço para interação, para a exposição de idéias e para a apresentação da solução dos casos. Uma equipe multidisciplinar estará disponível para esclarecimento de dúvidas que possam surgir no transcorrer do jogo.

\section{Descrição do Caso de Estudo}


No intuito de esclarecer o que está sendo proposto citamos a seguir um dos casos a serem resolvidos pelos participantes do jogo.

"Uma empresa quer entrar no nicho de EAD. A direção desta organização designa um funcionário para implementar a idéia. Entretanto, esse funcionário não entende nada de EAD e terá que começar do zero. Sente-se perdido. Qual o ponto de partida?

Os participantes do e-desafio terão que auxiliar este funcionário a tornar real o projeto, ajudando-o a solucionar dúvidas, problemas e apontando soluções que possam surgir durante o percurso".

\section{Considerações Finais}

O E-DESAFIO, está sendo implantado na PUCRS VIRTUAL pela equipe multidisciplinar de desenvolvimento de projetos especiais em EAD. Além disso, a perspectiva dos encontros síncronos, entre os grupos e os mediadores-líderes ${ }^{\mathrm{v}}$ traz à tona uma outra perspectiva do que é ensinar. No E-DESAFIO, não existem professores ministrando aulas, mas sim, professores mediadores, que reúnem, a partir das demandas das equipes, conhecimento e materiais a serem debatidos e que favorecem a construção conjunta do conhecimento. Primeiro, identificamos algumas dificultadades, como a resistência do grupo ao novo (no momento inicial) e ao ambiente de aprendizagem, pois ainda não havia sido utilizado. Contudo, entendemos que por ser um jogo interativo, que busca promover a criatividade, o espírito de equipe, a liderança e o aprendizado coletivo, estes obstáculos iniciais vão sendo dirimidos ao longo do tempo. Ao final deste primeiro E-DESAFIO, será desenvolvida uma avaliação coletiva, dentro da instituição, com as equipes participantes e a equipe gestora. Após estes resultados, novos programas serão criados e desenvolvidos.

\section{Referências}

BEHRENS, Marilda Aparecida. O professor em relação ao aluno. In: BEHRENS, Marilda Aparecida. Formação continuada dos professores e a prática pedagógica. Curitiba: Champagnat, 1996.

DELEUZE, G. \& GUATTARI. Mil Platôs. Rio de Janeiro: Editora 34, volumes 1 e 2 , 1995.

HABERMAS, Jürgen. Teoria de la acción comunicativa. Madrid: Taurus, 1987.

LÉVY, Pierry. Cibercultura. Rio de Janeiro: Editora 34, 1999.

MEDEIROS, Marilú Fontoura de; FARIA, Elaine Turk (Orgs.) Educação a distância: cartografias pulsantes em movimento. Porto Alegre: EDIPUCRS, 2003.

MORIN, Edgar. Ciência com consciência. Rio de Janeiro: Bertrand, 1996.

MORAN, José Manuel. Ensino e aprendizagem inovadores com tecnologias audiovisuais e telemáticas. IN: BEHRENS, Marilda A.; MASETTO, Marcos; MORAN, José Manuel. Novas tecnologias e mediação pedagógica. Campinas: Papirus, 2000. 
TAVARES, Kátia. Reflexões sobre a Formação do Professor On-line. Conect@ número 4 - fevereiro/2002.

http://www.revistaconecta.com/conectados/katia_discutindo.htm. Acessado em: 23de julho 2005.

VYGOTSKI, L. S. A formação social da mente: o desenvolvimento dos processos psicológicos superiores. $6^{\mathrm{a}}$ ed. São Paulo: Martins Fontes, 1998.

YIN, Robert K. Estudo de caso: planejamento e métodos. Trad. Daniel Grassi. 2. ed. Porto Alegre: Bookman, 2001.

\footnotetext{
${ }^{\mathrm{i}}$ Espaço de informação na Internet através do qual é possível acessar materiais didáticos, elaborados pelo professor, organizados de acordo com conteúdos curriculares de uma disciplina. Em geral, estes materiais são elaborados pelo professor para suas aulas presenciais e disponibilizados visando atender o desejo de reaproveitar os materiais que apresentam sua maneira de tratar o assunto.

ii Título dado nos tempos antigos aos construtores de pontes em virtude dos rituais religiosos que acompanhavam esta construção.

iii Aluno aqui é entendido como co-autor de toda a produção de conhecimento realizada dentro dos ambientes criados para fins de aprendizagem.

${ }^{\text {iv }}$ Qualquer recurso digital que possa ser reutilizado e ajude na aprendizagem. Estes objetos são adaptáveis à necessidades, habilidades, interesses e estilos cognitivos.

${ }^{v}$ Pessoas identificadas no grupo e na equipe que exerçam uma liderança nas equipes.
} 